\title{
Narration Through Gesture in Giulio Romano's 'Sala di Troia'
}

BETTE TALVACCHIA

The task of translating words into forms makes exacting demands on the artist's imaginative powers. The problems inherent in such a transmutation are compounded when the textual source consists of epic narration, with its characteristically lavish presentation of events and array of elaborate story-telling devices. The obligation imposed upon the artist to contrive convincing displays of action and to indicate sequence and the passage of time in static shapes is the underlying source of difficulty. How can an artist contain in such images the equivalent of an expansive verbal account of action?

One solution answers the challenge by indulging in a highly complex pictorial structure that teems with figures, descriptive gestures and intricate compositional patters. This Cecil B. De Mille approach, employing 'a cast of thousands,' was the one favored in an engraving of The Rape of Helen (Fig. 1), designed by Giulio Romano and executed by Marcantonio Raimondi. ${ }^{2}$ The removal of Helen from the house of Menelaus by Paris, son of the Trojan king Priam, was of course the act that provoked the battle between Greece and Troy, which ended in the destruction of Priam's realm.

In this version of the legend the artist presents us with an image of the violence and turmoil that surge around the classical temple where Helen had come to worship Venus. In the central foreground Paris literally yanks Helen - by grabbing at the bodice of her garment - toward the boat. His great physical effort is emphasized by his pose, crouched with one foot braced against the side of the boat for added support. Helen does not yield to her abductor, but pulls a sizeable clump of Paris' hair and looks back toward a would-be rescuer who tugs at another piece of her garment.

These frantic gestures, descriptive of the chaotic struggle, are surrounded by many others of fury and force. Companions of Paris in the crowded vessel actively participate in the project of coercing the resisting Helen aboard, or stretch outward in anticipation of catching the body that will 


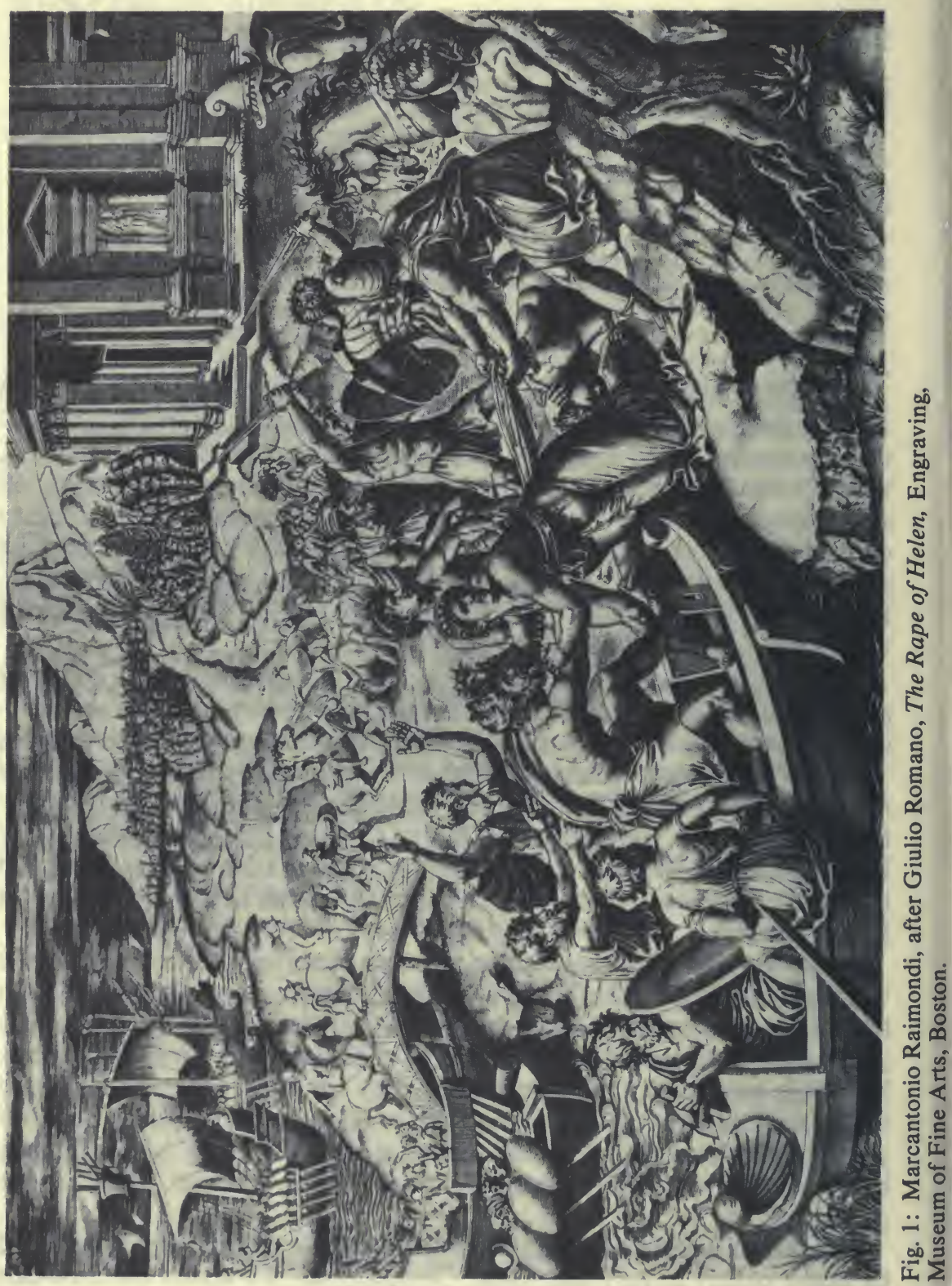


be hurled toward them. Warriors in the middleground engage in battle, and one whose spatial placement in or out of the boat is difficult to determine, throws up his arms in a gesture that is indicative of the alarm and confusion throughout the scene.

In dramatizing the moment of Helen's abduction the artist has also illustrated a ferocious battle, suggesting the one that will rampage for ten years before finally winning the release of Helen. An unnecessarily profuse escort of soldiers arrives in ships and engulfs the land; most of the troops are shown in such a reduced scale that they appear too remote even to be aware of the action that presumably initiates their movements. Instead of trying to limit the focus of the story of the rape of Helen, Giulio addressed the widest possible narrative by illustrating proleptically the consequences of the transgression at the very moment that it is committed. ${ }^{3}$

In another instance when Giulio put his skills to interpreting the story of Paris and Helen he invented a vastly different narrative technique. In 1538 Federico Gonzaga of Mantua called upon his court artist to decorate a room in his Ducal Palace with subjects from the history of Troy. The program given form by Giulio consisted of scenes based on Homeric stories, taken directly from the Iliad and from one specific compendium of mythological texts. ${ }^{4}$ Jacobus Micyllus gave this ancient anthology, the Fabularum Liber of Hyginus, its first modern edition in Basel in $1535 .^{5}$ Armed with these sources for accounts of the actions to be portrayed, Giulio invented a visual language of monumental character appropriate to the epic subject and to the importance of the duke's urban residence that is the site of the frescoes. The artist carried out a brilliant transformation of the literary images into visual ones, in large part, through a skillful handling of gestures. In particular, for the individual scenes that decorate the walls, the artist recounted a long and complex series of events, using few figures in carefully organized compositions. Giulio was able to tell a richly allusive story in a radically simplified format by establishing visual analogies through the repetition of postures and gestures, which carry narrative meaning for the attentive viewer.

The impressive setting created by Giulio for this cycle of Homeric legends has been known from its origin as the Sala di Troia. The room presents many facets of the story of Troy, including a panoramic scene of battle whose violence spreads without interruption across the entire ceiling depictions of the Trojan Horse, Laocoon, and Ajax Struck by Lightning. But in none of the stories narrated is Giulio's creative use of gesture more apparent than in the compositions that unfold the story of Paris (Fig. 2). Episodes from his life fill one long wall of the room, a vast expanse pierced only by a doorway that originally led out to a magnificent 


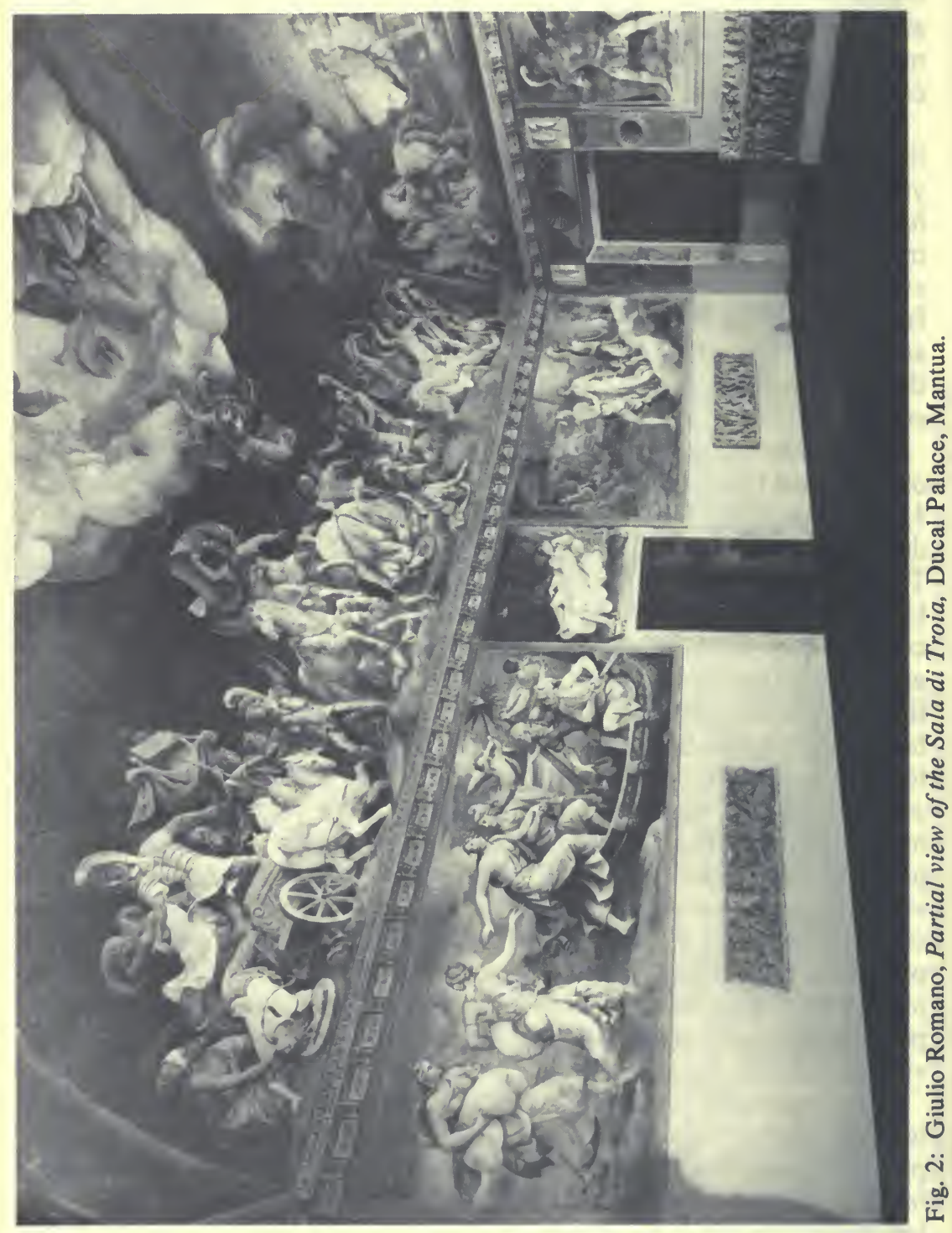


loggia. This wall faces the visitor who enters the Sala di Troia from the smaller rooms of Federico's apartment, and upon it begins the narration of this Trojan cycle.

The action is initiated in one of the most cohesive and thoughtfully arranged sequence of images in the room. The narrative follows closely, although selectively, the two stories in Hyginus that talk of Paris. The paintings have been composed with much care and ingenuity so that their structures reinforce the relationship of their contents. The first part of the drama commences with the Dream of Hecuba (Fig. 3). She is shown, immense and isolated, filling from end to end the space allotted to the panel delimited by the doorway. She reclines on a couch of expressly antique style, alone in her sleep, except for the attendance of a dark, winged creature hovering behind, his hand delicately touching her forehead. We are to understand from this portrayal the portent manifested on the eve of the birth of Paris, here recounted by Hyginus:

After Priam, son of Laomedon, had had many children by Hecuba, daughter of Cisseus or of Dymas, his wife, again pregnant, in a dream saw herself giving birth to a firebrand from which many serpents issued. When this vision was reported to all the seers, they bade her slay whatever child she should bear to avoid its being the ruin of the country. ${ }^{6}$

Giulio has masterfully given form to this nightmare with great economy of means, exploiting to the full the positions and gestures of the two figures and the details of the few props he has allowed himself. We comprehend that the male figure behind Hecuba is ethereal, not only because he is winged, but also because his lower body is encased in clouds. We perceive that he represents a dream by the placement of his fingers, touching the victim's forehead, transmitting a message into her sleep. The placement of the winged demon beside Hecuba's head accords well with Homeric descriptions of dreams. For example in Book Two of the Iliad, Homer portrays a vision of Agamemnon's in which 'Dream stood then beside his head in the likeness of Nestor'. ${ }^{7}$ Hecuba's head is turned toward the viewer as it rests on her hand, a traditional way of indicating sleep.

Elements included in the composition convey that the portent revealed by this spirit is a nightmare. The demon is painted a dark copper color, the expression on his face is threatening, and, most alarmingly, he holds aloft a fearful object whose image he relays to the sleeper: a burning torch. As she receives this baleful vision, Hecuba lies with her legs apart, one turned aside on the bed, another resting on a footstool on the floor. Her position, and that of the torch whose base emerges from her thigh, ${ }^{8}$ indicate the specific application of the nightmare; she dreams that she 
54 / Renaissance and Reformation

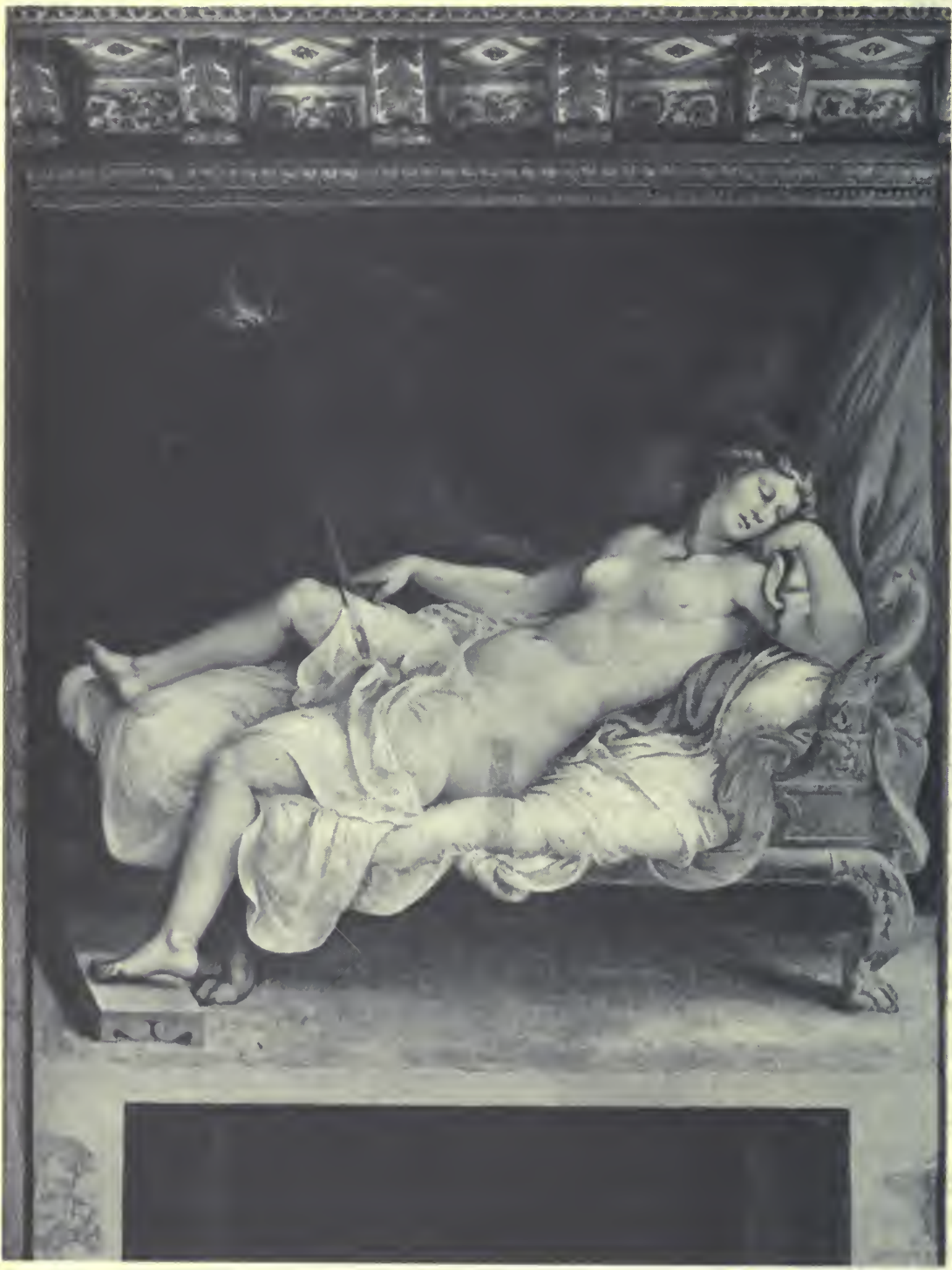

Fig. 3: Giulio Romano, The Dream of Hecuba, Fresco, Ducal Palace, Mantua. 
gives birth to this horrifying object instead of a child. The use of the torch with serpents confirms dependence of this depiction upon Hyginus, for 'The dream of the firebrand is found in all the writers, but the serpents in Hyginus alone."

The elaborate carvings featured on Hecuba's bed reinforce the air of menace in the scene, from the heavy animal claws that serve to support the couch, to the grotesque mask and recoiling head of a horse that form other decorative details. The horse's gesture of horror is underscored by the long, serpentine neck that transforms the horse into a monster.

The saga that has its ominous beginning just before the birth of the royal son who was to be responsible for the demise of his parents' kingdom proceeds in the fresco to the right of the Dream of Hecuba (Fig. 4). The background of this painting continues Hyginus' narrative exactly where it ended with the dream:

After Hecuba gave birth to Alexander, he was handed over to be killed, but the servants out of pity exposed him. Shepherds found the child, raised him as their own, and named him Paris. When he came to young manhood, he had a favorite bull. Servants sent by Priam to bring a bull to be given as prize in funeral games in Paris' honor, came and started to lead off the bull of Paris. He followed them and asked them where they were leading him. They stated that they were taking him to Priam ... [ to be a prize] for the victor in the funeral games of Alexander. $\mathrm{He}$, out of fondness for the bull, went down and won everything, even over his own brothers. In anger Deiphobus drew his sword against him, but he leaped to the altar of Zeus Herceus. When Cassandra prophetically declared he was her brother, Priam acknowledged him and received him in the palace. (XCI)

The sleeping figure of Paris, relegated to a secondary position in the painting always referred to as The Judgment of Paris, is doing no judging at all, but tends to his herd, which in this case is composed of bulls. Giulio's intention here was to continue the story of Paris' life, showing how he was spared by shepherds and raised to be one of them, surrounding him with the bulls that were to be the instrument of his recognition and return to Priam's household. In the posture of the seated figure, with left foot resting on a log, an echo can be found of the Paris in Raphael's famous representation of the Judgment, and this is probably also the source for the dog and the shepherd's staff(Figs. 5, 6). But instead of sitting upright, as in Raphael's model, here Paris leans back with his head supported by a bent arm, as if in sleep. This slight change has a great effect on the meaning of the fresco. Now the reclining Paris is a mirror image of the sleeping Hecuba, and the two figures, with their heads placed at similar angles, separated only by the stucco molding on the wall, physically and symbolically show the connection of the two scenes portrayed. 
56 / Renaissance and Reformation

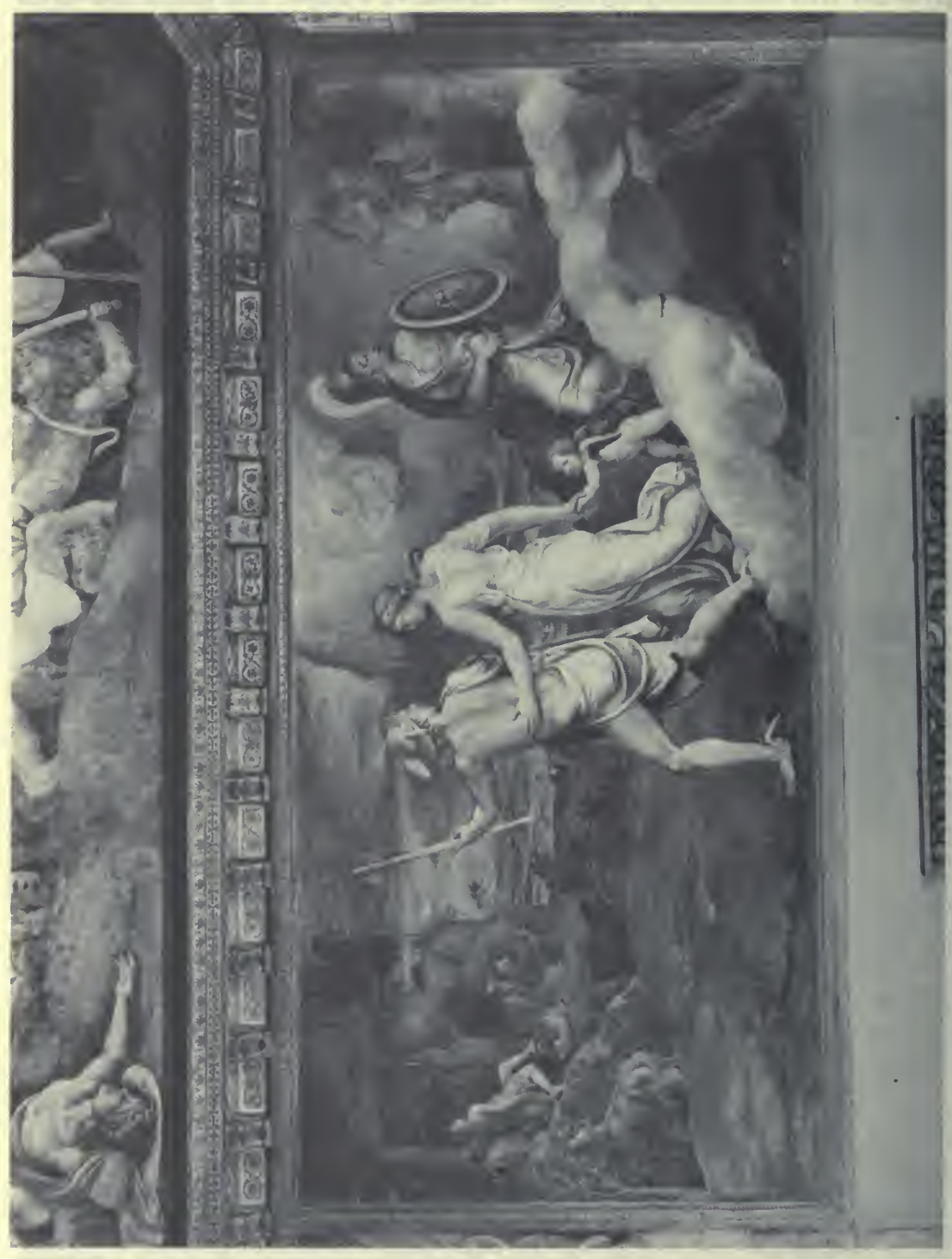

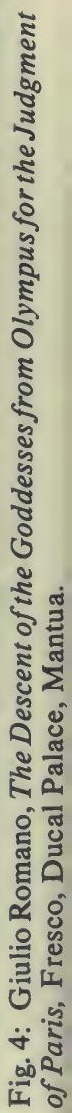


Renaissance et Réforme / 57

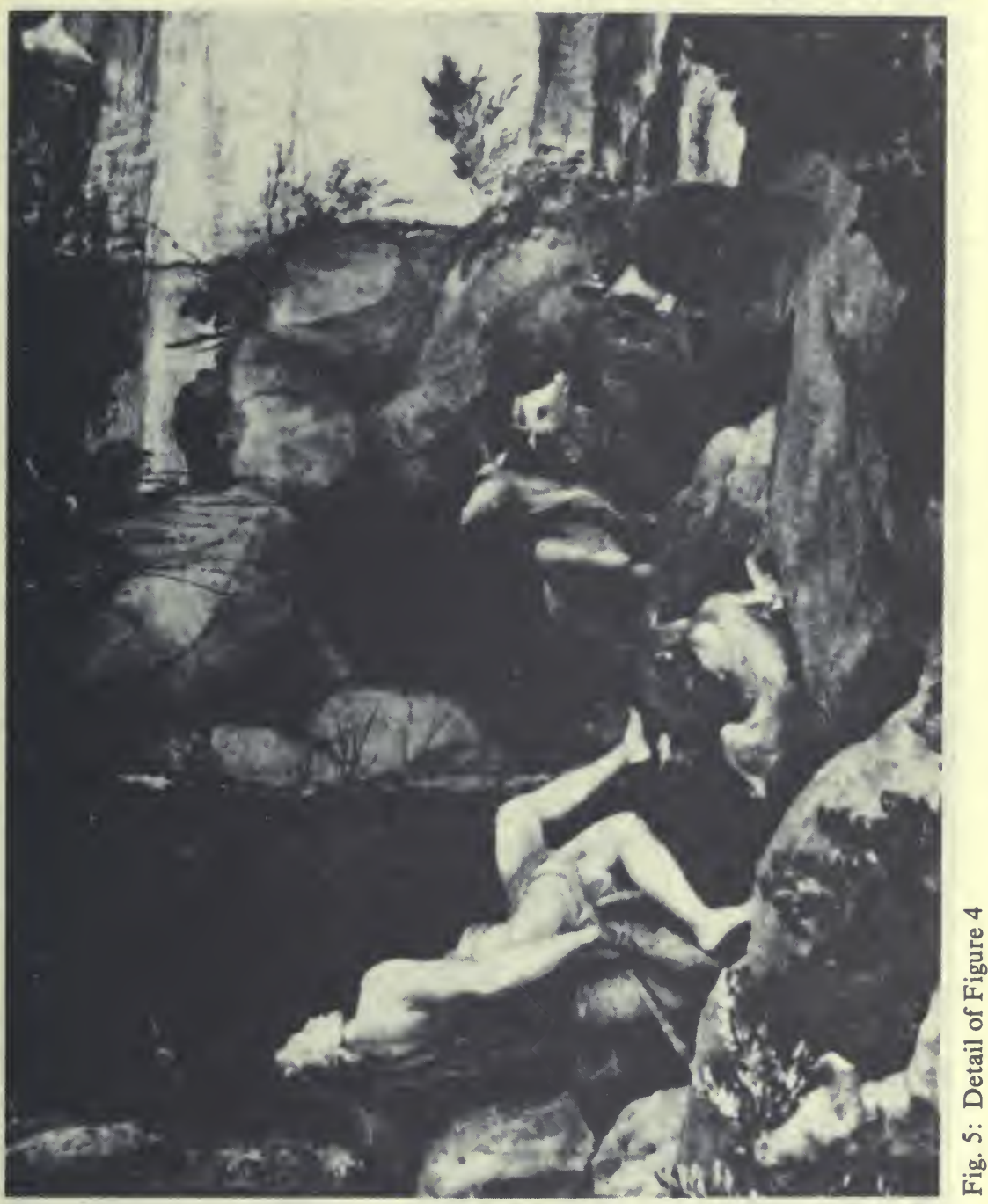




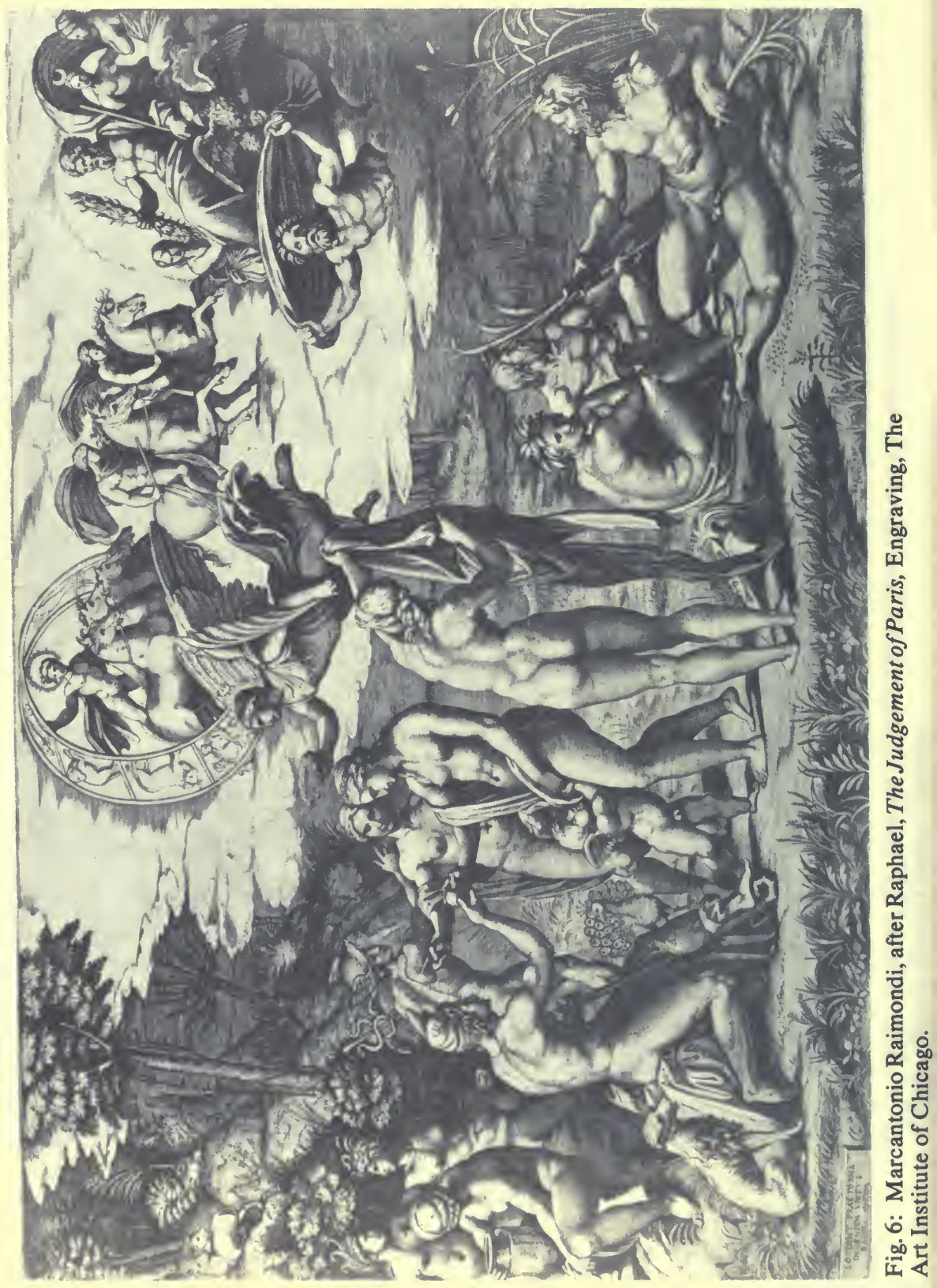


The pose shared by Hecuba and Paris was one developed in Giulio's repertoire to symbolize birth and allude to the relationship of mother to progeny, for the artist used a variation of it in another subject centering on the birth of a mythic figure. In the panel painting identified as The Birth of Bacchus ${ }^{10}$ (Fig. 7), the artist has placed Semele in the center of the scene, legs parted, with one foot resting on the ground and the other raised to a higher level. Below her lies the crying infant who throws his head back and by virtue of the way he is held by attendant figures, has been made to assume the same posture as his mother, repeated precisely, even to the gesture of the spread fingers of each hand. The place held by The Birth of Bacchus in the oeuvre of Giulio Romano is not fully understood, although a relationship to the decoration of the Ducal Palace has been suggested. ${ }^{11}$ The recurrence of this striking motif where the pose of the mother is reflected in that of her son may be a consideration that will help to clarify some aspects of the meaning of this painting. It certainly indicates that one part of Giulio Romano's approach to the use of gesture was systematic. Through repetition, certain poses come to take on a consistent meaning that can alert the viewer immediately to the significance of the subject before him.

The inclusion of the sleeping Paris in the Sala di Troia functions, then, in direct response to the adjacent figure of Hecuba, and indicates a stretch of narrative that has not been illustrated. The true subject of the fresco is not the act of judgment, but the descent of the three goddesses from Olympus to Mount Ida, where they will ask Paris for his fateful choice. Although Hyginus tells the story of the judgment in full, it was not illustrated in the Sala di Troia. Instead, we see Venus and Cupid (who alone engages the viewer with his stare), Minerva with her aegis, spear and helmet, and further back, Juno moving through a portal of clouds which she parts as she emerges, accompanied by her peacock (Fig. 4). They all follow Mercury, who points the way with his caduceus and the apple of discord, which, as Hyginus tells us gave rise to the impending competition.

Although the actual moment of judgment is nowhere shown on the walls of the Sala di Troia, subsequent events depicted in the room presuppose that the contest took place. The scene of the descent of the goddesses prefigures the outcome of the rivalry, in favor of Venus, by isolating her from the other two contending deites. Venus advances to embrace Mercury, flaunting confidence in her ability to beguile any man. The significance of this gesture is obvious as well as timeless, and would perhaps be diminished by any attempt at an elaborate gloss.

The remaining part of the wall is devoted to the notorious action that resulted in the Greek forces laying siege to Troy (Fig. 8). Paris is shown escaping to his boat with Helen in hand, who looks back to verify the 


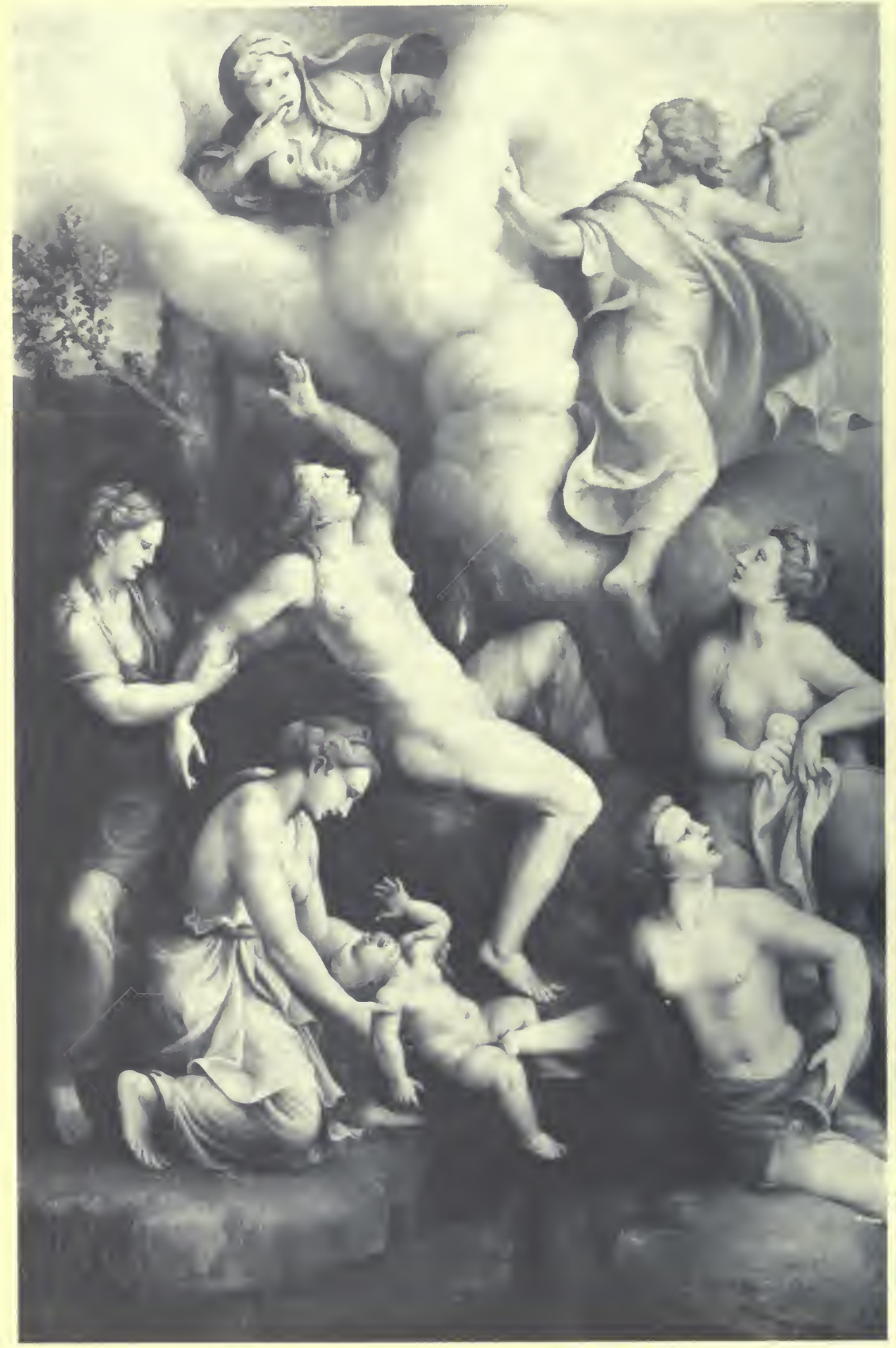

Fig. 7: Giulio Romano, The Birth of Bacchus, Oil on panel, The J. Paul Getty Museum. 
Renaissance et Réforme / 61

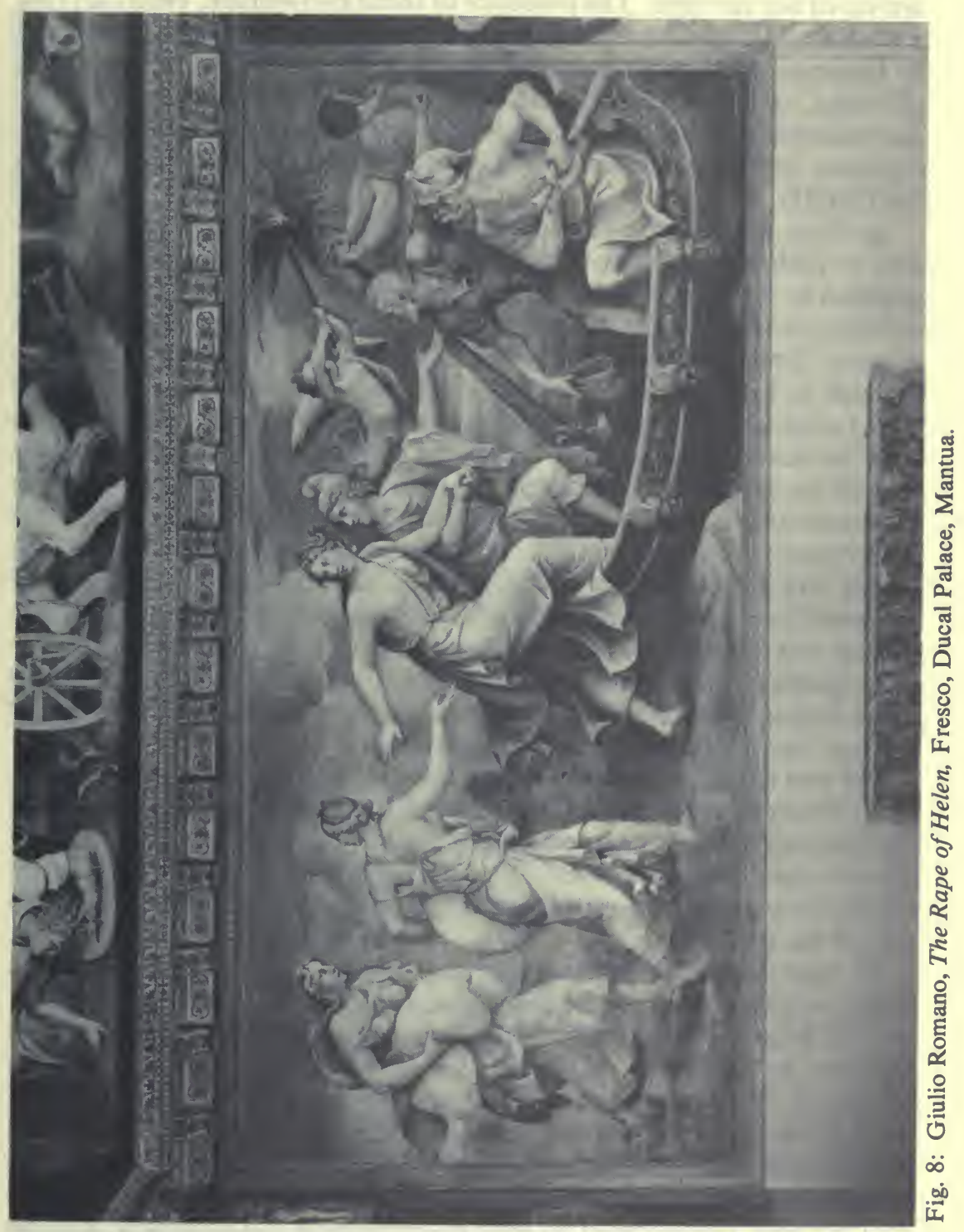


arrival of her servants. The presence of these two women, each carrying a bundle of her mistress' belongings, depends on the one detail recorded by Hyginus in his terse account of the deed: 'Alexander at the prompting of Venus, took Helen from his host Menelaus from Lacedaemon to Troy, and married her. She took with her two handmaids, Aethra and Thisiadie, captives, but once queens, whom Castor and Pollux had assigned to her'(XCII).

As these two women flee toward the boat, the first stretches out her arm to Helen, who extends hers back in return. Helen's other arm is grabbed by Paris who then signals forward to encourage the flight. This unbroken chain of arms, hands, and gestures ends with the strained arm of one of the men in the boat who points, it may be, to indicate pursuers or the path to be taken. But what this last figure does is to refer the viewer back to Hecuba's dream by pointing beyond the stucco frame toward the adjacent scene. And for good reason: the cupid who guides the transgression of the two lovers is illuminating their way with a torch identical to the ominous one that had ushered Paris into the world. There is one last admonition; even as the exploit is taking place, its consequence, which finally will be the burning of Troy, is forewarned. Giulio's addition of this motif to the fresco is completely independent of the literary description he was following. This is an instance where the repetition of a symbolic gesture - here the brandishing of a torch - compels the viewer to make a conceptual leap, supplying the narrative that stretches between the two manifestations of the same symbol.

The two torches, flaming with snakes, are each placed high in the corners of both frescoes, mirroring and visually responding to each other in the same way as do the sleeping figures of Hecuba and Paris. Each of the three scenes, then, forms part of a very tightly knit compositional interrelationship which hinges on a central panel, the birth of Paris, the inception of the entire tragedy.

To complete an assessment of the format and narrative affinities which interlace the three adjoining frescoes, one must step back to survey the length of the wall, so that a sweeping movement across the surface can be seen (Fig. 9). From the left enter four figures, draperies billowing, hurrying across to a waiting boat, under the guidance of a torch spewing serpents; from the right, three goddesses proceed down from Olympus toward the recumbent Paris, led by a fourth figure who holds aloft a staff, around which two snakes are entwined. The parallels are complete; the story is told with inventiveness and economy, and the result rages around the ceiling in images of the war caused by the actions of Paris.

In the examples that I have discussed gesture operates on another level beyond the simple expression of an attitude or emotional state. There is a 
Renaissance et Réforme / 63

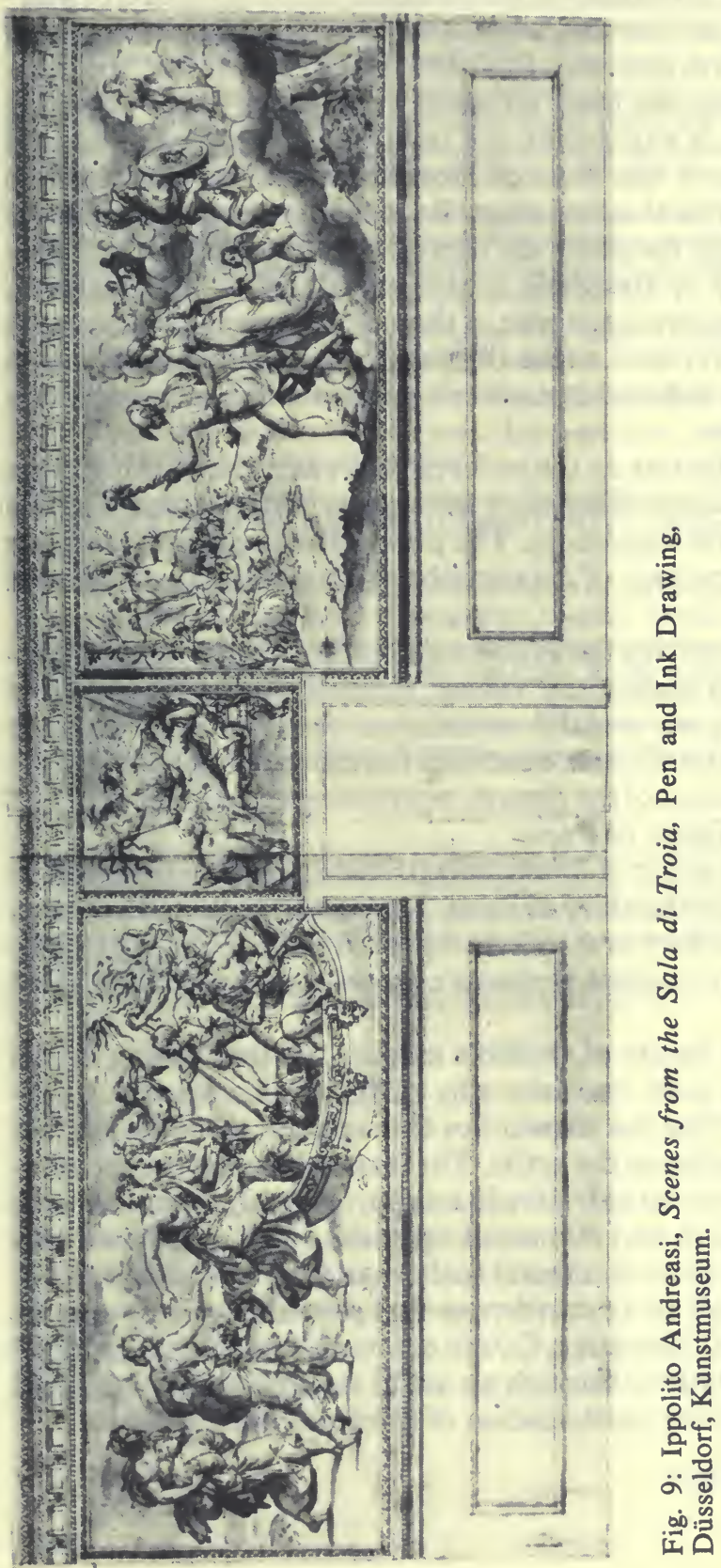


qualitative difference, for example, between the pointing motion of Mercury and the sleeping posture of Paris. In the first case the placement of the deity's hand and arm indicates to Venus, and to the viewer, the location of the judge whom she must ultimately persuade. Paris' reclining position, in contrast, is expressive not only of his sleeping state, but through its repetition of the pose of Hecuba, makes us link the two episodes by means of visual association. Once the connection is made we are compelled to supply mentally the narrative details that explain precisely the relationship of Hecuba's dream and Paris' act of judgment. With regard to the temporal sequence of the stories, there is a movement backward and forward in time, as the sleeping Paris, just before his return to Priam's household, echoes his mother's posture at the moment of her premonition of disaster.

With the scene of Hecuba as the point of reference, the burning torch of Cupid evokes an analogical memory through its juxtaposition with the premonitory torch of the nightmare. The parallel once again directs our attention back to the presage of catastrophe as Paris blindly carries out the decrees of Fate.

The process of recognizing the cyphers and supplying the implied connective details, which makes the viewer mentally traverse narrative time, is channelled by a carefully established compositional balance that, like the swing of a pendulum, describes the movement of an arc from Cupid's torch through that of the demon, continuing across Hecuba, and coming to rest in the figure of Paris.

Giulio chose not to set up a linear narrative progression from left to right across the walls for the story of Paris. Instead, he invented a system in which the viewer's ability to associate repeated postures and symbolic gestures with narrative content replaces chronological sequence as an ordering principle.

After analyzing the nature of Giulio's method of story-telling in this group of frescoes one must consider why he found this approach particularly apt. I suggest that the answer lies in the character of the job that the patron had imposed upon the artist. The task demanded the recounting of an extremely involved narrative in an appropriately grandiose epic style. If too many figures and numerous episodes were introduced into the frescoes, the requisite monumental scale would have been sacrificed. In response to a difficult set of desiderata that placed primary value on both monumentality and narrative, Giulio created a system that satisfied the duke's dual expectations through an artful manipulation of painted gestures that signalled the participation of informed viewers.

\section{University of Connecticut}


1 This article is based on material taken from my doctoral dissertation, Giulio Romano's Sala di Troia Synthesis of Epic Narrative and Emblematic Imagery (Stanford University 1981). I am now preparing this manuscript for publication.

2 See the convincing attribution to Giulio given by Elizabeth Tietze-Conrat 'The Rape of Helena by Giulio Romano' in Print Collector's Quarterly 27 (1940) 496-500. The central group in the engraving is linked to a drawing, in its turn associated with a roundel in the Palazzo del Te. This reuse of individual figures and motifs is typical of Giulio's working method.

3 One must presume that the two events are conflated here. In the Medieval romance versions of the abduction of Helen, where the moment of passionate recognition takes place in the temple of Venus, no fighting is needed to induce Helen's departure. See Margaret R. Scherer 'Helen of Troy' Metropolitan Museum of Art Bulletin 25 (1967) 371.

4 For a full discussion of this source and its use in the Sala di Troia see my dissertation pp. 56-60 and passim.

5 For information on the text of Hyginus see H.J. Rose Hygini Fabulae (Leiden 1934).

6 The Myths of Hyginus Mary Grant trans. (Lawrence, Kan. 1960) 82. All excerpts from the Fabulae will be taken from this edition.

7 The Iliad of Homer Richmond Lattimore trans. (Chicago 1967) II.20; cf. Malcolm M. Willcock $A$ Companion to the Iliad (Chicago 1976) 17: 'Dreams are usually said to stand at the head of the sleeper.'

8 There are some points that remain unclear about this motif. The extension of the torch in front of Hecuba's thigh emerged with a cleaning of the frescoes, finished in 1968. It does not appear, however, in Ippolito Andreasi's drawing of the fresco, carried out in 1568, indicating that it had already been painted over by that time (see Figure 9). My hypothesis is that it was a second thought of Giulio's, to point out more dramatically the relationship between the vision and the birth of Paris. It may then have been covered rather soon, reflecting a change of taste in a later possessor of the room, perhaps during the regency of Margherita Paleologa and Cardinal Ercole Gonzaga.

9 The Myths of Hyginus 82.

10 Burton B. Fredericksen Catalogue of Paintings in the J. Paul Getty Museum (Malibu 1972) no. 32. The identification of the subject of the painting as Semele and Bacchus, proposed by Fredericksen, is problematic. Important details of this story are missing, whereas they are present in a study for a Birth of Bacchus preserved in a drawing from the Ellesmere Collection (Hartt, Figure 461).

11 Frederick Hartt Giulio Romano (New Haven 1958) $211-7$. 